\title{
Pharmacy Pricing and Out-of-Pocket Health Care Expenditure in India
}

\author{
J Cyril kanmony* \\ Department of Economics, Scott Christian College, India
}

Received: June 18, 2018; Published: June 26, 2018

*Corresponding author: J Cyril Kanmony, Professor Emeritus, PG \& Research Centre, Department of Economics, Scott Christian College (Autonomous), Nagercoil-629003, Kanniyakumari District, Tamil Nadu, India

Keywords: Out-of-Pocket; APL Status; BPL Status; Pharmaceutical Products; Generic Medicines; Dilapidated Condition; Hesitant; Profit Margin; Price Control; Quite Apathetic; Clinical Drug Trials; Status Sensitive; Public Health Care Services; Expenditure Per Capita

\section{Mini Review}

In India the out-of-pocket (OOP) health care expenditure (about $70 \%$ ) is much more in comparison with many other countries (only $10 \%$ in the UK). The high OOP leads to impoverishment of many families. Every hospital admission pushes many families from APL status into BPL status (addition per year is around 6\%). High prices for medicines and other pharmaceutical products, high doctor's fee and prescription of high priced medicine for ordinary diseases and unnecessary operations are some of the reasons for high 00P. Of all these reasons the ever rising prices of pharmaceutical products (many branded drugs are sold at 200 to $500 \%$ profit margin though many are under price control) is the most important one. Prices of many drugs are fixed arbitrarily, much higher than their cost of production (100 to $200 \%$ more). In the dog-eat-dog world everyone is trying for abnormal profit and so are the pharmaceutical companies. The aim is to produce pills for all ills. Doctors prescribe costly medicines mostly lured by the commission assured. Though there are generic medicines (India is considered as the generic pharmacy of the world) for many illnesses many doctors prescribe high priced patented medicines. There is also commission for doctors (as much as $40 \%$ ) from referral, diagnostic and scan centres.

People's widespread preference for quality health care provided by private hospitals also raises the 00P. Government hospitals are in dilapidated condition and so people are hesitant to approach them though they are meant to serve the needy and poor rural people. The facilities available are not good $(73 \%$ of people live in villages but only $25 \%$ of medical services reach them; there was a shortfall of 3022 doctors in PHCs, and 17525 specialists in CHCs). The number of doctors available per every one million people is also very low in India, even lower than that of Pakistan, Sri Lanka and South Africa (only 758 doctors per million people in India against 7519 in Cuba, 978 in Pakistan, 881 in Sri Lanka and 818 in South Africa). The reason for the low efficiency and poor performance of public hospitals in India is that government is quite apathetic towards them (as a percentage of GDP it is only 3.9\% against $17 \%$ in the USA). India's current health expenditure per capita is also very low ( $\$ 63$ against $\$ 9,818$ in Switzerland). In India, in certain years the budget allotment for health sector does not exhibit any increase (-0.31\% between $2010-11$ and 2014-'15). Hence the state of public health in India is much poor and in the Global Burden of Disease India occupies 154th rank, much lower than that of China, Sri Lanka and Bangladesh.

The doctors in public hospitals are not considerate enough to a patient hearing to the poor rural patients. There are countless incidents of the poor treatment meted out in government funded hospitals and clinics. So they prefer private hospitals to public hospitals, which are neither regulated nor monitored (16 states have no legislation) while even petty shops have been forced to register under any one of the laws. As they are not regulated they are charging exorbitant rates for even common ailments. In many private hospitals due to asymmetrical information medical professionals deceive patients by compelling them to buy more drugs or undergo a wrong treatment than the optimal or the appropriate. They prescribe unnecessary and expensive medicines for fairly routine problems. A large number of injections administered for common ailments such as fever and cough are unnecessary. Fraudulent activity, over medication, unnecessary surgeries, illegal clinical drug trails, excess usage of higher technologies and following of cut and commission policies are the salient features of the Indian private health care sector. However they are patient-friendly and trying to give quality care and fast relief to their ailments. 
At the same time people are also 'status sensitive'. It is another reason for flourishing of private hospitals at the cost public hospitals. Though good medicines are available in public hospitals at free of cost (for diseases like polio and snake and dog bites), only very few approach them. Not only rich but also elite and educated people are reluctant to make use of public hospitals. Even poor and marginalised are approaching these centres only for very common ailments and for others they opt for private hospitals. Hence their utilisation is very poor (only about $20 \%$, and at the time of Independence the share of modern medical care provided by private sector was only $8 \%$ but now it provides $80 \%$ of all outpatient care and $60 \%$ of all inpatient care). In the study conducted by the author also the utilisation of public health care services even by the aged is only $31 \%$; only 62 out of 200 surveyed. Further as a very low proportion of population in India is covered by health insurance scheme (only 11\% in India against 85\% in the USA) the OOP health care expenditure is very high.

The reasons for high OOP are many. But the losers are patients and so the OOP has to be cut down. Of all the policies aimed at reducing OOP, the simplest and the most effective will be the implementation of a cost control initiative. If people opt for private hospitals price reduction alone cannot bring down out-of-pocket health care expenditure. It can be achieved by a combination of ways which include reducing prices of pharmaceutical products, regulating and monitoring private hospitals, enhancing the operational efficiency of public hospitals and changing the attitude of people towards public hospitals and the approach of the medical professionals towards health problems of the poor.

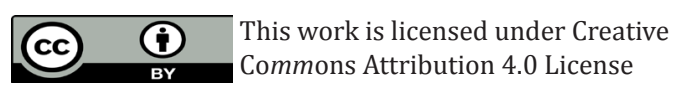

Submission Link: https://biomedres.us/submit-manuscript.php

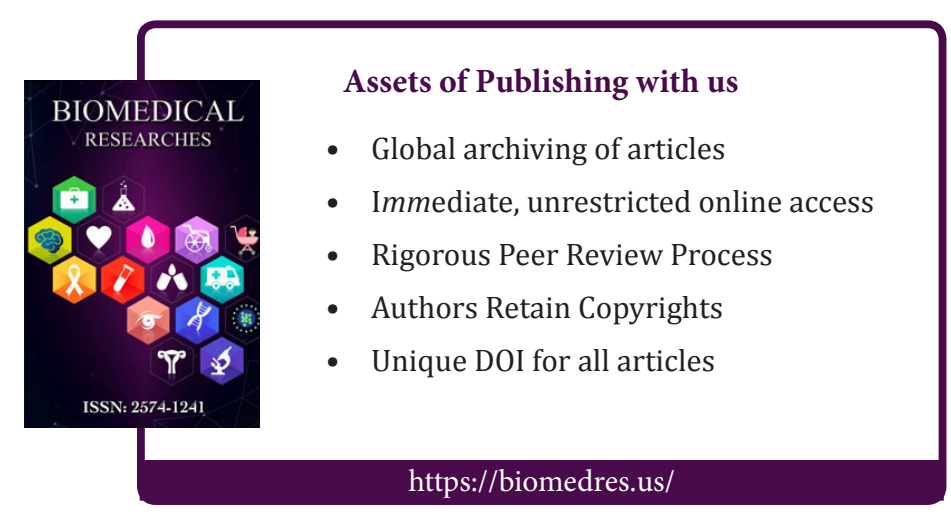

